\title{
The rationale for FK 506 in inflammatory bowel disease
}

\author{
James C Reynolds, MD, Dan R Trellis, MD, Kareem Abu-Elmagd, MD, John Fung, MD
}

JC REYNOLDS, DR TRELLIS, K ABU-ELMAGD, J FUNG. The rationale for FK 506 in inflammatory bowel disease. Can J Gastroenterol 1993;7(2):208-210. FK 506 is a novel macrolide immunosuppressant which is more potent than cyclosporine. Recent evidence that cyclosporine has efficacy in the treatment of inflammatory bowel disease (IBD) led to the development of a new protocol using FK 506. FK 506 has been shown to produce substantially greater survival in liver transplant patients than cyclosporine, with fewer side effects. Inhibition of lymphocyte production of cytokines interleukin (IL)-2, IL-3 and interferon gamma requires 10 to 100 times greater concentrations of cyclosporine than of FK 506. Rejection episodes are less frequent and side effects fewer in patients receiving heart, kidney or liver transplants following treatment with FK 506 than with cyclosporine. Thus, the development of a new, potent immunosuppressive agent with a greater safety profile than cyclosporine provides a new opportunity to identify an effective therapy for patients with IBD resistant to corticosteroids.

Key Words: Cyclosporine, FK 506, Immunosuppressant, Inflammatory bowel disease, Interleukiins, Macrolide

\section{Justification du FK-506 dans la maladie intestinale inflammatoire}

RÉSUMÉ: Le FK-506 est une nouvelle macrolide immunosuppressive plus puissante que la cyclosporine. De récentes données au sujet de la cyclosporine et de son efficacité dans le traitement de la maladie intestinale inflammatoire a mené au développement d'un nouveau protocole utilisant le FK-506. Le FK-506 s'accompagne d'un taux de survie nettement plus élevé que la cyclosporine chez des patients ayant subi une transplantation hépatique et provoque moins d'effets secondaires. L'inhibition de la fabrication lymphocytaire des cytokines interleukines (IL)-2, IL-3 et de l'interféron gamma requiert des concentrations de 10 à 100 fois plus grandes de cyclosporine que de FK-506. Les épisodes de rejet sont moins fréquents et les effets secondaires moins nombreux chez les patients qui ont reçu une transplantation du coeur, d'un rein ou du foie, suite au traitement avec FK-506 qu'avec la cyclosporine. Ainsi, la mise au point d'un agent immunosuppresseur nouveau et puissant doté d'un profil d'innocuité plus sûr que celui de la cyclosporine, procure de nouvelles possibilités en termes d'efficacité du traitement pour les patients atteints de maladie intestinale inflammatoire résistante aux corticostéroïdes.

Department of Medicine, The University of Pittsburgh School of Medicine, Pittsburgh,

Pennsylvania, USA

Correspondence and reprints: Dr JC Reynolds, Division of Gastroenterology and Hepatology, University of Pittsburgh Medicine Center, Presbyterian University Hospital, DeSoto at O'Hara Streets, Merzanine Level, C Wing, Pittsburgh, PA 15213-2582, USA
W HILE THE INCITING EVENTS THAT initiate the activity in inflam. matory bowel disease (IBD) remain an enigma, an over-activated immune response plays a major role in both Crohn's disease and ulcerative colitis (1). Medical therapy, therefore, has been aimed at modulating this aggressive immune response.

The cornerstones of medical therapy for IBD include both sulphasalazine (and its derivatives) and corticosteroids. Typically, use of these agents will successfully manage 85 to $90 \%$ of patients with IBD. In addition to the 10 to $15 \%$ who do not respond to conventional therapy, another group of patients will experience adverse effects from long term corticosteroid treatment. These undesirable effects include mood changes, hypertension, glucose intolerance, osteoporosis, aseptic nec. rosis and cataracts.

Other immunosuppressives that have had success in treating other 'auto-immune' diseases have therefore been investigated to treat patients with IBD who are refractory to or intolerant of corticosteroids. 6-Mercaptopurine (6-MP) and azathioprine have proven efficacy in patients with refractory IBD - $(2,3)$. Unfortunately, these agents frequently require three months of therapy before demonstrating a response and while effective in 60 to $70 \%$ of patients with refractory IBD, 30 to $40 \%$ of patients with active disease do not respond.

Methotrexate has shown early promise in treating patients with re- 
fractory IBD, including those who did not respond to 6-MP or azathioprine (4). Methotrexate typically requires eight to 12 weeks to exert its effect. Controlled studies with this agent are in progress.

While it is not known how 6-MP, azathioprine or methotrexate modify the immune response, cyclosporine, another agent that has been studied in patients with refractory IBD, affects the immune cascade by inhibiting the production of $\mathrm{T}$ lymphocyte cytokines, particularly interleukin-2. Cyclosporine has revolutionized the field of organ transplantation by significantly decreasing the frequency of organ rejection and improving patient and graft survival. Cyclosporine has also been shown in a controlled study to have modest efficacy in patients with refractory Crohn's disease (5). It acted quickly, usually within two weeks of beginning therapy. Long term use of cyclosporine in treating Crohn's disease, however, has not been as efficacious $(6,7)$.

Cyclosporine may also have a role in fulminant ulcerative colitis. In an uncontrolled study, intravenous cyclosporine alleviated the need for colectomy in patients with fulminant ulcerative colitis who had failed corticosteroids (8). Controlled trials are currently being performed.

The toxicities of cyclosporine, although apparently not that frequent in the IBD studies, have been well documented in patients undergoing organ transplantation. These include hypertension, renal insufficiency, glucose intolerance, opportunistic infections and lymphoproliferative tumours.

\section{REFERENCES}

1. Stenson W, MacDermott R. Inflammatory bowel disease. In: Yamada T, ed. Textbook of Gastroenterology. Philadelphia: JB Lippincott Co, 1991:1588-645.

2. Present D, Korelitz B, Wisch N, et al. Treatment of Crohn's disease with 6-mercaptopurine; a long-term, randomized, double-blind study. N Engl J Med 1980;302:981-7.

3. Adler D, Korelitz B. The therapeutic efficacy of 6-mercaptopurine in refractory ulcerative colitis. Am J Gastroenterol 1990;85: 717-22.
FK 506 is a newer agent (discovered in 1984) that is currently being investigated in organ transplantation. FK 506 is a macrolide antibiotic derived from Streptomyces tsukubaensis a microorganism found in soil. Although structurally different from cyclosporine, the mode of action of FK 506 is similar to cyclosporine; it also acts by inhibiting the production of $T$ lymphocyte cytokines but through different binding proteins. FK 506 in vitro is approximately 100 times more potent than cyclosporine in inhibiting the induction of T lymphocyte proliferation (9). FK 506 is more effective than cyclosporine in preventing rejection in liver, cardiac and renal transplantation and in improving patient and graft survival (10-12). Transplant patients with chronic rejection of the transplanted organ while taking cyclosporine have been salvaged when switched to FK 506. FK 506 is also more reliably absorbed than cyclosporine when ingested orally since it does not require the presence of bile (13). Although its toxicities are very similar to those of cyclosporine, FK 506 causes a lower incidence of hypertension (14).

Since cyclosporine appears to be effective in the therapy of refractory Crohn's disease and in refractory fulminant ulcerative colitis, it is possible that a medication that blocks the immune response at the same location, yet is more potent and has fewer adverse effects, may have a role in treating patients with refractory IBD. Because of this rationale, we have begun a three-month pilot study to investigate the efficacy and safety of FK 506 in

4. Kozarek R, Patterson D, Gelfand M, et al. Methotrexate induces clinical and histologic remission in patients with refractory inflammatory bowel disease. Ann Intern Med 1989;110:353-6.

5. Brynskov J, Freund L, Rasmussen S, et al. A placebo-controlled, double-blind, randomized trial of cyclosporine therapy in active chronic Crohn's disease. N Engl J Med 1989;321:845-50.

6. Brynskov J, Freund L, Norby Rasmussen S, et al. Final report on a placebo-controlled, double-blind, randomized, multicentre trial of patients with IBD who are refractory to or intolerant of corticosteroids.

\section{FK 506 STUDY OUTLINE}

The specific aims of this study are to: identify the lowest dose of FK 506 that exerts a beneficial effect on active IBD; determine the safety of FK 506 in patients with IBD; and determine whether FK 506 improves objective measures of disease activity including laboratory, endoscopic and radiographic findings, as well as improving symptoms. Patients were enrolled in this study if they had active IBD for longer than six months that had been inadequately controlled by corticosteroids, or if they had active IBD and were intolerant of corticosteroids. Crohn's disease is being studied separately from ulcerative colitis because these disorders differ with respect to the symptoms, complications and frequency of extraintestinal manifestations. This has led previous investigators to establish distinctive indices of disease activity. Standard definitions of these disorders will be used as defined in the inclusion and exclusion criteria. Early results are promising that these goals will be met. Several patients being treated for pyoderma gangrenosa had resolution of symptoms of Crohn's disease.

Chronic fistula drainage, unresponsive to all other medications, closed in response to FK 506. FK 506 has been well tolerated, and renal toxicity can be avoided by dose adjustment. The preliminary investigation indicates the need for further studies on the efficacy of FK 506 in the treatment of IBD.

cyclosporin treatment in active chronic Crohn's disease. Scand J Gastroenterol 1991;26:689-95.

7. Archambault A, Feagan B, Fedorak R, et al. The Canadian Crohn's Relapse Prevention Trial (CCRPT). Immunol Microbiol Inflammat Dis 1992;102:A591.

8. Lichtiger S, Present D. Preliminary report: Cyclosporin in treatment of severe active ulcerative colitis. Lancet 1990;336:16-9.

9. Kay JE, Moore AL, Doe SEA, et al. The mechanism of action of FK 506 Transplant Procs 1990;22:96-9.

10. Fung J, Abu-Elmagd A, Jain R, et al. A 
randomized trial of primary liver transplantation under immunosuppression with FK 506 vs cyclosporine. Transplant Proc 1991;23:2977-83

11. Armitage J, Kormos R, Fricker F, Starzi T. The clinical trial of FK 506 immunosuppression in adult cardiac transplantation. In: FK 506 First
International Congress, Pittsburgh. 1991:52. (Abst)

12. Shapiro R, Jordan M, Scantlebury V, et al. FK 506 in clinical kidney transplantation. In: FK 506 First International Congress, Pittsburgh. 1991:55. (Abst)

13. Jain A, Fung J, Tzakis A, et al. Comparative study of cyclosporine and
FK 506 dosage requirement in adult and pediatric orthotopic liver transplantation. In: FK 506 First International Congress, Pittsburgh. 1991:4. (Abst)

14. Fung J. Clinical side effects of FK 506. In: FK 506 First International Congress, Pittsburgh. 1991:65. (Abst) 


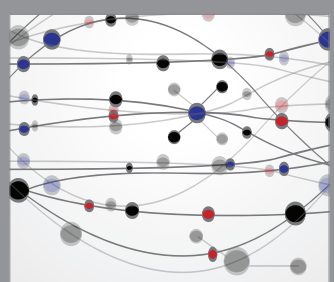

The Scientific World Journal
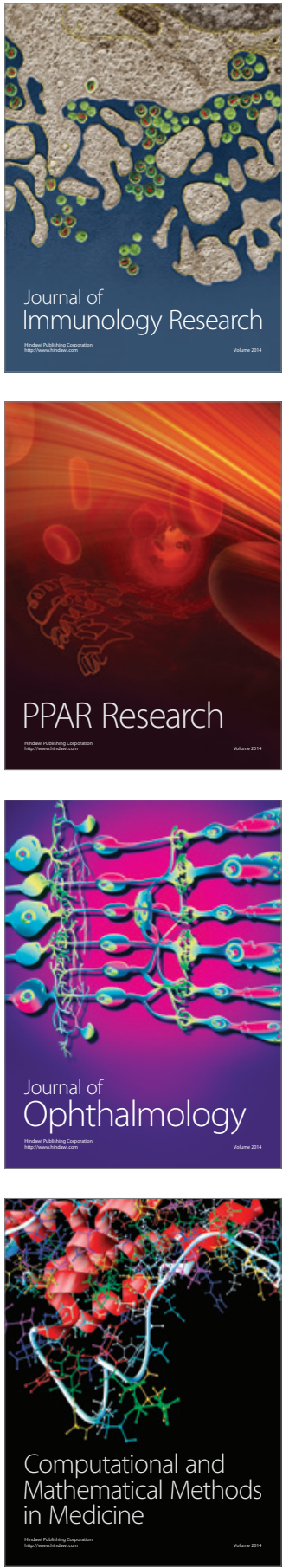

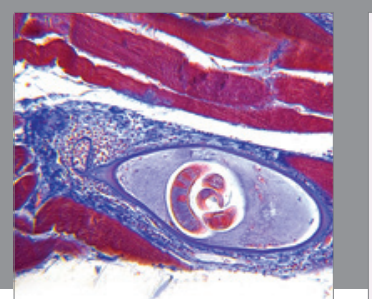

Gastroenterology Research and Practice

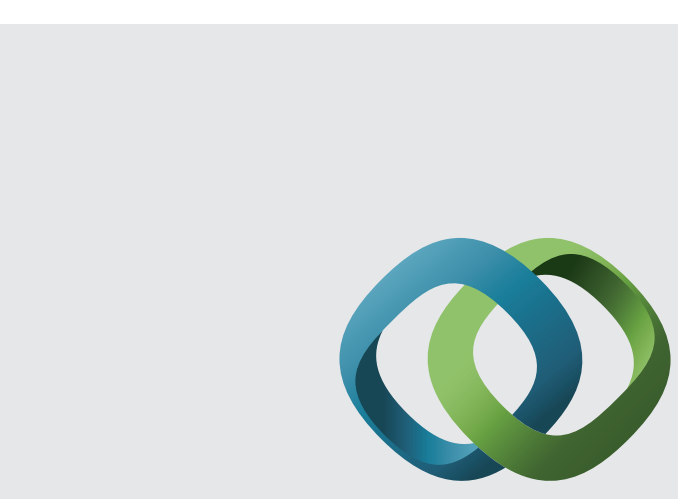

\section{Hindawi}

Submit your manuscripts at

http://www.hindawi.com
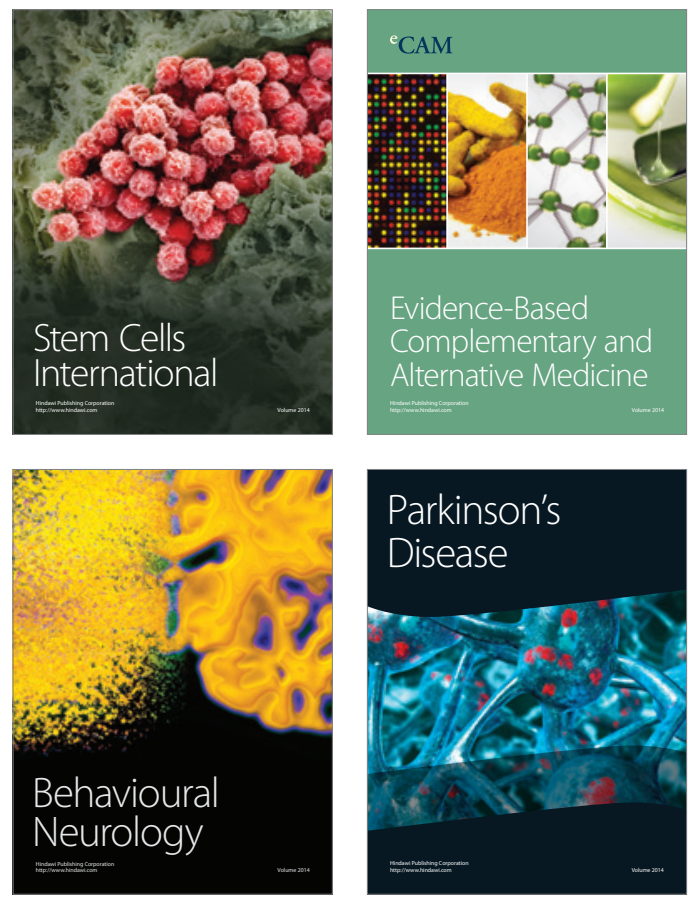
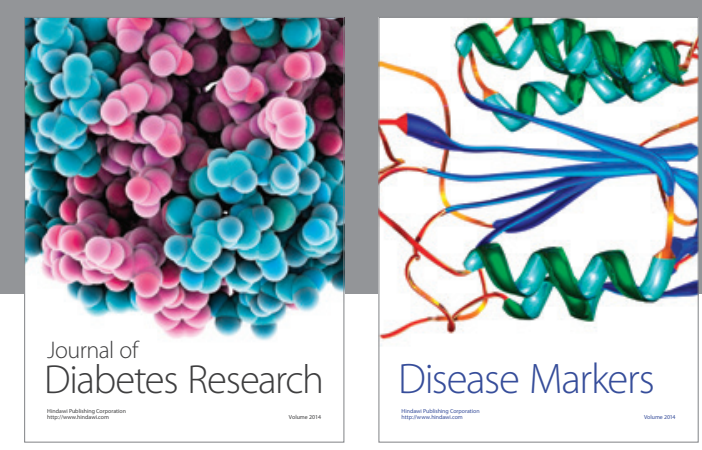

Disease Markers
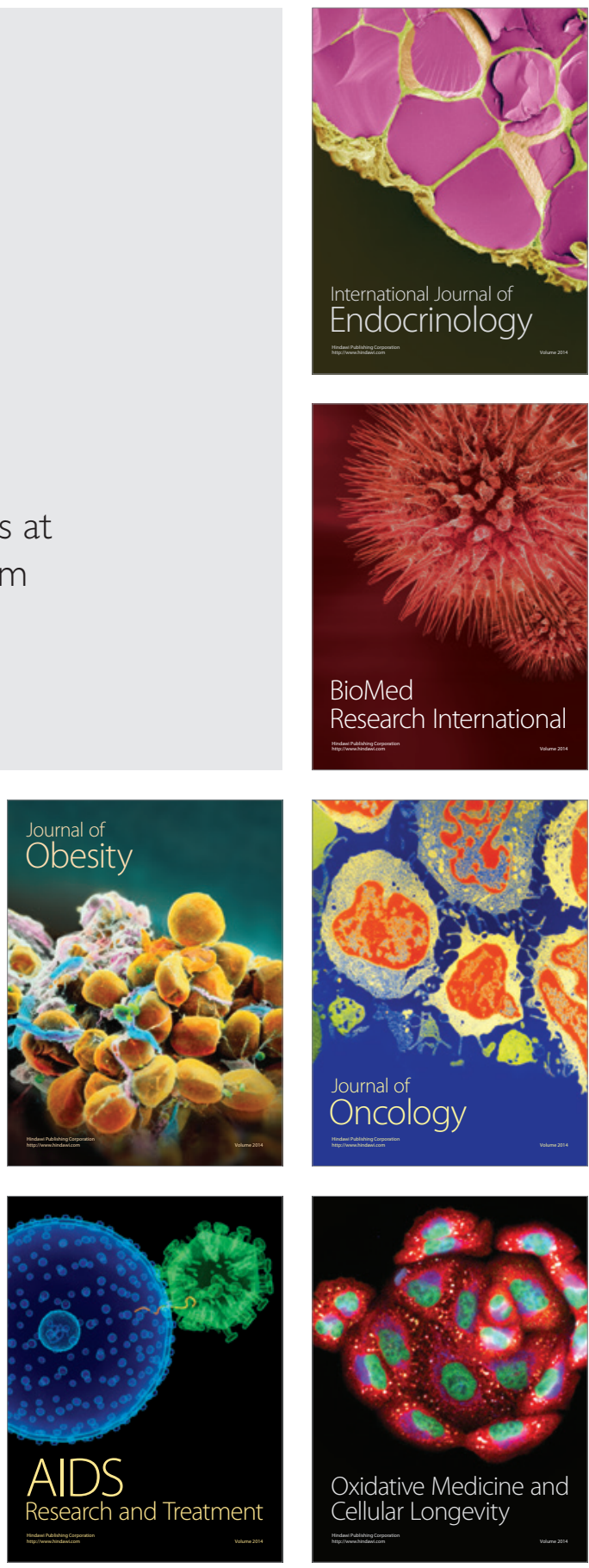